\title{
How Do Test Type And Test-Taking Skills Affect Mathematics Performance Among High School Students: A Nigerian Example
}

\author{
Olujide O. Dixon, Stella Y. Erinosho \\ Olabisi Onabanjo University ${ }^{1,2}$ \\ Nigeria
}

\begin{abstract}
The study examined the interplay of test taking skills ((before-test, during-test and after-test strategies) and performance in open ended mathematics test among secondary school students in Lagos State, Nigeria. The sample consisted of one thousand and six (1006) Senior Secondary (SS) II students selected from eighteen (18) schools in Lagos State, Nigeria. Two instruments, open-ended mathematics tests in short answer and extended typesand Test-Taking Skill Scale (TSS), were administered one after the other. Findings show that the three categories of test-taking skills contributed significant positive variance to the prediction of students' performance on the tests, with test-preparation skill contributing the most. Differences were found in the performance on the test types, higher on extended open-ended test. Also, the high, average and low scorers reported different use of test-taking skills, with high scorers recording the highest use of testing strategies. The findings have implications for supporting students to develop and use appropriate test-taking skills for more success in mathematics.
\end{abstract}

\section{Introduction}

Assessment is useful in the teaching of mathematics as it enables teachers to understand the cognitive knowledge of students in solving problems. Knowing how well the students uunderstand mathematical concepts and principles, their mathematical reasoning and proficiency is useful to understand their problem-solving ability and to assist them to overcome their conceptual difficulties and learning needs. Tests are commonly used as assessment tools to measure cognitive learning and proficiency of students. Cognitive tests that focus on determining mastery of instructional content are referred to as achievement tests [1]). Two types of achievement tests are typically used to measure cognitive learning in schools- the open-ended and objective formats, each of which has its unique features. Multiple-choice tests provide an easy and flexible tool of assessing learning outcomes across a broad range of content in a given time, with minimal measurement error, due to the objectivity and reliability in scoring [2]. On the contrary, openended or essay tests are attractive options to measure complex outcomes requiring deep understanding and higher thinking skills or abilities $[2,3]$, competence in organizing ideas and presenting in coherent and meaningful manner. In mathematics, essay tests provide opportunity for testees to analyse problems and exhibit the structure and dynamics of their thought processes in solving a problem whereas multiple choice can be restrictive, requiring choice of the correct option among given alternatives [4]. However due to variations in scoring standard and relatively narrow content coverage, essay tests may be less reliable than multiple-choice tests in providing the true score of cognitive ability of a student, although the answering mode on multiple choice also makes it susceptible to guesses.. Empirical studies have compared performance across the two test types [3,4,] While some studies tend to make inference demonstrating higher performance in multiple choice item [4,5], others found no difference across the item types [6].

Students must be proficient in test-taking for the test to adequately serve as a measure of their mastery of a learning content. Academic success is influenced by utilizing appropriate approaches in studying and learning [2]. Poor performance in a subject may not solely be that students lack ability, but because of inappropriate learning approaches. Using appropriate learning approaches involves applying good study habit to become proficient in the subject content and the techniques to exhibit the learned knowledge during exams. Achieving success in exams require that students demonstrate competence in expressing the learned knowledge on a test. It is possible to have knowledge of the content of a subject but perform poorly on a test due to poor test-taking strategies. The ability to utilise appropriate strategies to demonstrate competence and perform at optimal level on a test is referred to as test-taking skills. Such skills enable students to recognize what to do before-test, during- 
test, and after-test to achieve success $[8,9]$. Beforetest skills include the study strategies prior to a test such as practicing old questions or self-quizzing; during-test skills are the strategies employed while taking a test which include time management, structure and organization, correctness of information, control of test anxiety and test-wiseness; whereas after-test skills include use of hints and feedback on test answers or scoring rubrics for managing future testing situation. Appropriate use of the test skills enable students to learn the "tricks of testing for success".

Previous studies report positive relationship of test-taking skills with student motivation to learn and attitude towards learning [10]; impact on reducing tension and anxiety of examinees [11]; locus of control [12]; and academic achievement [8]. On the contrary, test-taking skill deficit is found to have negative effect on test performance and also cause a lack of test wiseness $[8,13]$. A study [14] found that college students with low test-taking skills "had difficulty concentrating, were more concerned about lack of time, and felt more nervous, frustrated, and uncertain during exams" Other researchers found significant difference between high and low achieving mathematics students; high achieving students reported use of effective testing strategies more frequently than low achievers [12,15]. Additionally, recent studies have explored the gender gap in mathematics learning strategies with inconsistent findings. While some studies found that girls exhibit greater learning strategies than boys and are superior to boys in achievement, others revealed boys outperforming girls $[16,17,18]$.

In Nigeria, open-ended test items are commonly employed in classroom assessment and in the National Certification examinations conducted by West African Examination Council (WAEC) and National Examination Council (NECO). Two variations of open-ended test formats are traditionally the short answer and extended (essay) format. Both test formats require different response modes: short answer, unlike essay, do not necessarily require showing detailed workings to an answer. Evidence from the Chief Examiners' reports in the examinations consistently show the challenges encountered by large number of students that undermine their achievement, including poor preparation, inability to interpret and reason logically through word problems, deficiency in writing answers to the required degree of accuracy and poor time management. This is more evident in open-ended problems that require logical reasoning, mathematical thinking processes and organizational skills to develop an answer. These observations are indicators of poor testing behavior and lack of test taking skills of students.

Whereas the literature has identified the use of testing skills as a contributing factor to learning, little attention has focused on assessing its impact on mathematics performance among students in Nigeria. Much of the existing studies focused on facilitating instructional strategies in mathematics, which seem not to yield much improvement in achievement. Hence, it might be worthwhile to shift attention to the approaches that students utilize in test preparation and test taking as a contributing factor to achievement. The assumption is that the extent of utilising test skills is affected by the test type. Hence, it is important to explore how skills that students apply in dealing with testing situations is affected by test type, and the interaction with achievement. This study examined the interplay of test types, test-taking skills and performance in mathematics, measured by scores on two formats of open-ended test items (short answer and extended or essay), among secondary school students in Lagos State, Nigeria.

\section{Research Questions}

1. What is the comparative advantage of two formats of open-ended test - extended and short answer on performance in mathematics among senior secondary school students?

2. What is the predictive ability of test-taking skills (before-test, during-test and after-test strategies) on performance in open-ended test in mathematics?

\section{Hypothesis}

The study tested the hypothesis that reported use of test taking skills will not be affected by the achievement level in mathematics, at 0.05 level of significance.

\section{Theoretical Framework}

The study draws on the Skill Acquisition Theory propounded by Deskeyer [20] to explain the cognitive and behavioral changes in skill construction and development. The theory provides a cognitive framework on progression in skill development, progressing from novice to proficiency stage. According to the theory, skill acquisition is a form of learning involving "initial representation of knowledge, through initial changes in behavior to eventual fluent, spontaneous, largely effortless, and highly skilled behavior". It delineates the forms of knowledge utilization in skill learning as declarative knowledge followed by procedural knowledge and then automatization. Declarative knowledge is descriptive, involving learning of facts, concepts and pieces of information through direct instruction and observation, which can be stored in the memory for future use. Procedural knowledge draws on declarative knowledge to apply the learned rules for a 
task at a given time. Automatization entails utilization of procedural knowledge through suitable practice to display the learned skill and behavior with proficiency i.e. "complete fluency and spontaneity, rarely showing any errors" [20]. Practice is critical to automatization of procedural knowledge through constant engagement with same or related tasks, which should be engaging, purposeful, and distributed [21].

Skill Acquisition Theory (SAT) is relevant in knowing how students use mathematics knowledge and develop skills to deal with the operations, logic and rules that characterize learning the subject. Mathematics is ultimately about problem solving, requiring that learners apply their declarative knowledge of learned rules acquired through instructional activities to work on specific tasks and express their knowledge of the task. Doing well in the subject would therefore require that students learn the rules and operations in addition to developing appropriate skills to express the learned knowledge in testing situation. Testing skills are acquired through regular practice and repetition of similar problems as part of test preparation and achieving fluency in answering questions. How well learners utilize the procedural skills to the point of "fluent, spontaneous, largely effortless, and highly skilled behavior" [21] of learned knowledge will determine their overall performance. This they could do through use of appropriate testing skills and engagement in practice and repetition of expected or similar problems on a test.

\section{Method}

\subsection{Design}

The study adopted descriptive research design to investigate the inter-relatedness of mathematics achievement and test taking skills among Senior Secondary (SS) II students in public schools in Lagos State, Nigeria.

\subsection{Sampling and sample}

A total sample of one thousand and six students participated in the study. Multi-stage sampling technique was adopted to select eighteen public senior secondary school from three of the six districts in Lagos State. Then, proportional sampling was adopted in selecting $10 \%$ of the total senior secondary schools in each district. Random selection of 70 SSII were initially drawn from each school, although only those that completed the instruments were used in the analyses.

\subsection{Instrumentation}

Three instruments were used to collect data: TestTaking Skill Scale (TSS), Mathematics Restricted (short answer) Open-ended test (MROT) and Mathematics Extended Open-ended test (MEOT). TSS is a 5-point Likert scale (adapted from $[8,10]$ consisting 28 items distributed into three sub-scales: test-preparation strategies e.g., practice old mathematics tests within the time limits (6 items); during-test strategies with three sub-scales of structural organization e.g., look through the test before starting to answer the questions (4 items), time management e.g., spend a lot of time on difficult questions (4 items), test-wiseness e.g., leave time to proofread, skip difficult question and come back to it later (6 items); and after-test strategies e.g., use comments on returned script to re-learn the content $(8$ items) On TSS, students reported the way each item on the scale is a reflection of their testing behavior on a 3-point scale. The Kaiser-Meyer Olkin measure of sampling adequacy shows that the item sample is factorable $(\mathrm{KMO}=.657)$. In addition, 23 of the 28 items correlate at least 0.3 with at least one other item, which is acceptable factorability. The internal consistency reliability (Cronbach alpha) for the subscales are: test-preparation strategies $(\alpha=0.60)$; during-test strategies $(\alpha=0.75)$, time management $(\alpha=0.85)$, test-wiseness $(\alpha=0.83)$ and after-test strategies $(\alpha=0.78)$.

MEOT and MROT are achievement tests covering five topics that were already taught in the schools. MEOT consists of 7-item extended response items that student have the option to answer any five with detailed workings e.g, Use quadratic formula to solve $3 x^{2}-5 x+1=0$ while MROT is a twenty (20) short answer items test covering the same topics as MEOT and students are required to supply the correct answer without necessarily showing the workings. e..g.,, The value of equation $2 x^{2}+13 x=15$ is ..... The test-retest correlation coefficient (r) are 0.64 and 0.69 for MEOT and MROT respectively.

\section{Results}

To determine statistical significance of differences in performance on the test formats, the raw scores were converted to percentage and the means standardized with a $\mathrm{z}$ test. The negative $\mathrm{z}$-score (see Table 1) indicates that the scores of the participating students fall below the expected average on MROT ( $\mathrm{z}$ $=-0.95)$, but slightly higher on MOET $(z=0.27)$. The range shows that the scores are more spread out on MOET (range=47) than MORT (range = 35). 
Table 1. Descriptive statistics on MROT and MEOT

\begin{tabular}{lcccccc}
\hline \hline $\begin{array}{l}\text { Test } \\
\text { type }\end{array}$ & Mean & SD & z & Min & Max & Range \\
\hline MROT & 29.44 & 5.47 & -0.95 & 21.0 & 56.0 & 35.0 \\
MOET & 34.97 & 6.21 & 0.27 & 15.0 & 62.0 & 47.0
\end{tabular}

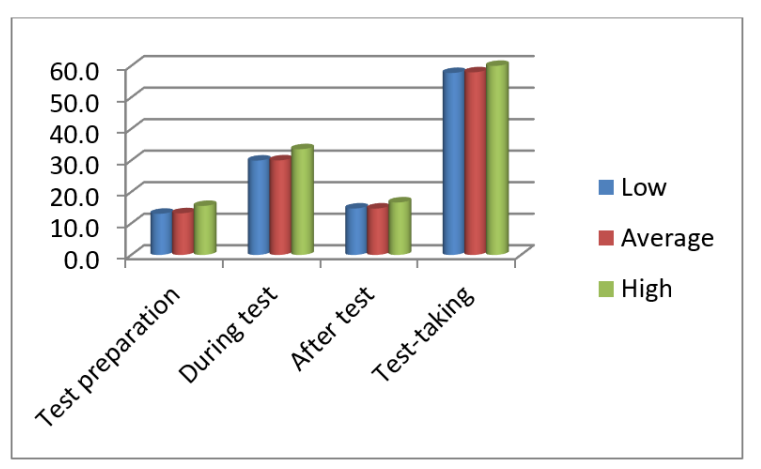

Figure 1. TSS scores by achievement levels on MOET

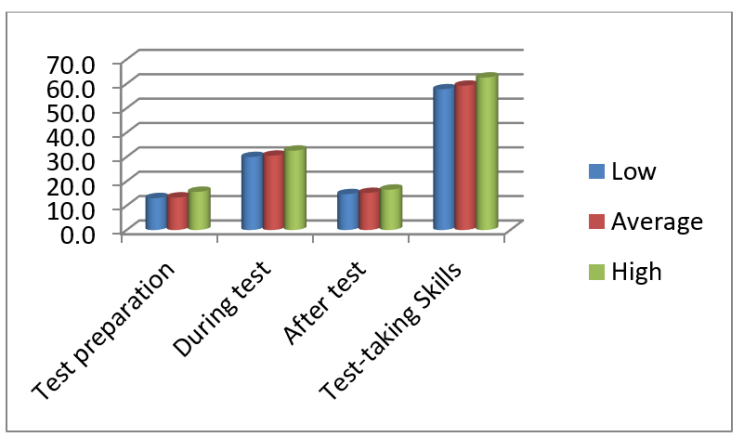

Figure 2. TSS scores by achievement levels on MORT

Table 2. Regression analysis

\begin{tabular}{lllllll}
\hline & MOET & & & \multicolumn{3}{c}{ MORT } \\
\hline Predictors & $\mathrm{B}$ & $\beta$ & $\mathrm{r}$ & $\mathrm{B}$ & $\mathrm{B}$ & $\mathrm{r}$ \\
\hline Before test & $0.84^{* *}$ & 0.26 & 0.37 & $0.92^{* *}$ & 0.45 & 0.38 \\
& & & & & & \\
During-test & $0.70^{* *}$ & 0.33 & 0.34 & $0.23^{* *}$ & 0.13 & 0.26 \\
& & & & & & \\
After-test & $0.42^{* *}$ & 0.27 & 0.19 & $0.74^{* *}$ & 0.27 & 0.34 \\
$\mathrm{R}^{2}$ & 0.36 & & & 0.27 & & \\
$\mathrm{~F}$ & & & & & & \\
$* \mathrm{p}<.05$ & $66.88^{*}$ & & & $69.61^{*}$ & & \\
\hline
\end{tabular}

Correlation and multiple regression analyses were undertaken to examine the relationship between mathematics performance and test-taking skills (test- preparation, during-test and after-test skills). As shown in Table 2, each sub-scale of TSS correlates positively with performance on the test, albeit low. However, considering the sample size, the values are sufficient enough to suggest that students with high scores in test-preparation, during-test and after-test skills tend to have high scores in a free-response test format. Test preparation had a stronger coefficient $(\mathrm{r}=0.37$ and .38$)$ for MOET and MORT respectively. In addition, the multiple regression model indicate that all three predictors produced comparable variance on both test types $\left(\mathrm{R}^{2}=.0 .36, \mathrm{~F}=66.88, \mathrm{p}<0.05 ; \mathrm{R}^{2}\right.$ $=.0 .27, \mathrm{~F}=69.61, \mathrm{p}<0.05)$. The coefficients of multiple regression determinants $(\beta)$ for MOET $(0.26$, 0.33 and 0.27 ) imply that $26 \%, 33 \%$ and $27 \%$ of the variance in performance on the test is accounted for by changes in the variables of test-taking skills. Similarly, $\beta$ values for MORT indicate that test-skills variables contributed $45 \%, 13 \%, 27 \%$ to the variance in performance on MORT. These values are considered enough to determine the statistical significance of the coefficient of determination. Test preparation $(b=0.84)$, during test $(b=0.70)$ and after test $(b=0.42)$ had significant positive regression weights, indicating that students with high scores on each scale were expected to record high mathematics performance, after controlling for the other variables in the model. Similar values are obtained for MORT $(92 \%, 23 \%$ and $74 \%)$. The $\mathrm{b}$ values indicate that for every additional test preparation skill, during test skill and after test skill, it is expected that mathematics performance increased by $84 \%, 70 \%$ and $42 \%$ respectively on MOET in comparison with $92 \%, 23 \%$ and $74 \%$ on MORT. By implication, test preparation skill had the strongest weight compared to other skills on both test types. However, whereas after test skill had the least weight for MOET, the weight is least for during-test skill on MORT.

In order to determine the mean variation on TSS according to performance level, the mean percent scores on both tests are classed as high $(>70)$, average $(<70>40)$ and low $(<40)$, in line with the grading convention in schools. The score distribution according to achievement level is shown graphically in Figures 1 and 2.

Table 3 shows the variation in mean scores on TSS according to achievement levels. The F values in Table 3 show that there is significant difference in the reported use of the test skills $(p<.05)$. Multiple comparison analyses in Table 4 reveal that the highest difference is recorded by the high scoring group when compared with the other scorers. The highest difference in performance was obtained on test preparation while the least difference is on after test skills. 
Table 3. Variations in test-taking skills according to achievement level

\begin{tabular}{|c|c|c|c|c|c|c|c|}
\hline & & & Sum of Squares & Df & Mean Square & $F$ & Sig. \\
\hline \multirow[t]{11}{*}{ MOET } & Test preparation & Between Groups & 5.604 & 2 & 2.802 & 8.158 & 0.02 \\
\hline & & Within Groups & 2427.653 & 1003 & 2.420 & & \\
\hline & & Total & 2433.257 & 1005 & & & \\
\hline & During test & Between Groups & 2.034 & 2 & 1.017 & 12.102 & 0.00 \\
\hline & & Within Groups & 9978.212 & 1003 & 9.948 & & \\
\hline & & Total & 9980.247 & 1005 & & & \\
\hline & After test & Between Groups & 1.325 & 2 & .662 & 10.217 & 0.001 \\
\hline & & Within Groups & 3058.440 & 1003 & 3.049 & & \\
\hline & & Total & 3059.765 & 1005 & & & \\
\hline & & Within Groups & 18083.825 & 1003 & 18.030 & & \\
\hline & & Total & 18133.622 & 1005 & & & \\
\hline \multirow[t]{9}{*}{ MORT } & Test preparation & Between Groups & 6.022 & 2 & 3.011 & 19.180 & 0.01 \\
\hline & & Within Groups & 1846.913 & 724 & 2.551 & & \\
\hline & & Total & 1852.935 & 726 & & & \\
\hline & During test & Between Groups & 5.858 & 2 & 2.929 & 21.357 & 0.00 \\
\hline & & Within Groups & 5942.208 & 724 & 8.207 & & \\
\hline & & Total & 5948.066 & 726 & & & \\
\hline & After test & Between Groups & 3.734 & 2 & 1.867 & 19.619 & 0.00 \\
\hline & & Within Groups & 2183.140 & 724 & 3.015 & & \\
\hline & & Total & 2186.875 & 726 & & & \\
\hline
\end{tabular}

$* \mathbf{p}<.0 .5$ 
Table 4. Multiple comparisons analysis of TSS means

\begin{tabular}{|c|c|c|c|c|}
\hline & \multicolumn{2}{|c|}{ Test-taking skills } & \multirow{2}{*}{$\begin{array}{c}\text { Mean } \\
\text { Difference } \\
(\mathrm{X}-\mathrm{Y})\end{array}$} & \multirow[t]{2}{*}{ Sig.p } \\
\hline & $(\mathrm{X})$ & (Y) & & \\
\hline \multirow{3}{*}{$\begin{array}{l}\text { Before } \\
\text { Test }\end{array}$} & Low & Average & -.715 & $* *$ \\
\hline & Low & High & -.751 & $* *$ \\
\hline & Average & High & -.283 & \\
\hline \multirow[t]{3}{*}{ During test } & Low & Average & -.410 & \\
\hline & Low & High & -.672 & $* *$ \\
\hline & Average & High & -.377 & \\
\hline \multirow[t]{3}{*}{ After test } & Low & Average & -.650 & $* *$ \\
\hline & Low & High & .691 & $* *$ \\
\hline & Average & High & -.493 & $* *$ \\
\hline
\end{tabular}

** $\mathrm{p}<.05 ; \mathrm{X}, \mathrm{Y}$ indicate mean score by achievement classification

\section{Discussion and Conclusion}

Drawing from the findings on the test performance, it seems that the students were more open to problems in extended than restricted format. A plausible reason for the difference in performance on the test types might be as a result of the tasks embedded on each format and the scoring strategy used. The restricted open-ended test requires testees to supply the specific correct answer without necessarily showing detailed mathematical reasoning for a problem whereas the extended format requires elaborate, logical and constructive workings in response to the test item. In scoring the open-ended restricted problems, the scoring rubrics were entirely based on the correctness of an answer (holistic scoring), which have been found not to provide detailed diagnostic feedback on performance [20]. However, the scoring rubrics for the extended format adopted analytic method, which were based on the correctness and the mathematical reasoning for an answer. The analytic scoring strategy is perceived as a "part-to-whole judgement approach" [24] in which points are assigned for specific key dimensions of a problem, and the aggregation of the points formed an overall score; implying that even an incorrect answer could attract scores depending on the demonstration of the correct mathematical reasoning. Studies have reported on the usefulness of analytic rubrics for guiding the improvement of students learning 25].

The predictive analyses confirmed previous findings $[2,15]$, indicating positive interaction of test skills and performance in mathematics. A significant percentage of the variance in performance on the tests is accounted for by changes in the test-taking skills. The values obtained are significant enough to be considered in explaining the variation in mathematics performance among students. A student who scored highly on the test also likely reported higher use of test-taking skills. Contributing the highest variance is preparation strategy, indicating that more of the students reportedly allocate time to practice and getting information that could help before taking a mathematics tests. Practice before a test is an effective strategy for students to get information and knowledge that could enhance their confidence during-test and hence enhance achievement.

The high-scorers obtained higher mean scores on the three subscales of TSS than low-scorers, confirming findings in prior studies $[2,12,13]$ that high scorers, more often than low scorers, reported using appropriate strategies more frequently in taking mathematics test. Studies indicate [15] that low achievers typically tend to demonstrate low level of motivation and minimal enthusiasm to engage in learning or to expend effort to complete a task. Additionally, low achievement negatively affects motivation to learn, attitude towards test and confidence to apply testing strategies for success [23]. Confidence and attitude towards problem solving are critical filters in mathematics achievement [24, 25]. Confidence help learners to develop interest in learning a subject; confidence feeds motivation and then success. Test-taking skills are reported to have significant relationship with the motivation to learn mathematics and attitude towards tests [11] and to eliminate feelings of tension and anxiety that may affect performance [27]. It can therefore be deduced that improving the testing behavior of students will have significant impact on low performing students.

Contributing the least variance on both test types is after test skills, suggesting that a large number of the students reportedly underuse hints and feedback from marked scripts. A plausible reason from experience is because teachers hardly return marked answer scripts with comments to help students locate their deficiencies. Poor usage of after-test skills limits the opportunity for students to use the cues from their errors or learning deficiency to improve future testing behaviour. Therefore, the significance of the findings of this study is in classroom instructional practices. Mathematics teachers would help students to learn and display their knowledge more effectively by integrating test taking strategies and study techniques into classroom instruction. The study by [27, 28] has confirmed the possibility of training students on testing strategies and the effectiveness of the training for enhancing academic performance. Hence, with increasing pressure to raise performance in mathematics, the need to emphasise instructional preparation for testing has become imperative for classroom assessment. Some strategies to support students to improve testing skills are through regular practice exercises, frequent testing and constructive feedback, access to scoring rubrics, and continuous self-quizzing. 


\section{References}

[1] Haladyna, T. M., (1997). 'Writing Test Items to Evaluate Higher Order Thinking'. Allyn \& Bacon: MA 02194-2310.

[2] Abdolhussein Shakurnia, Houshang Alijani, Shahnaz Najjar, Hossein Komeili and Hussein Elhampour. (2013), The Effect of Two Assessment Methods on Exam Preparation and Study Strategies: Multiple Choice and Essay Questions'. Iranian Journal of Medical Education, 13(4), pp. /3-18.

[3] William E. Becker and William B. Walstad (1994). 'Achievement Differences on Multiple-Choice and Essay Tests in Economics', American Economic Review, 84(2), pp.193-96.

[4] Popham, W. J., (2010). 'Everything school leaders need to know about assessment'. Corwin Press.

[5] Hickson, S., Reed, W. R., \& Sander, N. (2012). 'Estimating the effect on grades of using multiple-choice versus constructive-response questions: Data from the classroom'. Educational Assessment, 17(4), pp. 200-213.

[6] Hickson, S., \& Reed, B., (2011). 'More evidence on the use of constructed-response questions in principles of economics classes'. International Review of Economics Education, 10(2), 2011, pp. 28-49.

[7] Fathabadi J, Saif A. (2007). 'Investigating the effects of type of assessment (Essay and Multiple-Choice) on students' approaches to studying and exam perception strategies between students with high and low achievement'. Journal of Education and Psychology. 3(4): 21-46.

[8] Biçak, B., (2013). 'Scale for test preparation and test taking strategies'. Educational Sciences: Theory and Practice, 13(1), pp. 279-289.

[9] Dodeen, H. M., Abdelfattah, F., \& Alshumrani, S., (2014). 'Test-taking skills of secondary students: the relationship with motivation, attitudes, anxiety and attitudes towards tests'. South African Journal of Education, 34(2), pp. 01-18.

[10] Doden, H., (2008). 'Assessing test-taking strategies of university students: Developing a scale and estimating its psychometric indices'. Assessment \& Evaluation in Higher Education, 33 (4), pp.409-419.

[11] Taie, M., (2014). 'Skill acquisition theory and its important concepts in SLA'. Theory and Practice in LanguageStudies, 4(9), pp.1971-1976.

[12] Hong, E., Sas, M., \& Sas, J. C., (2006). 'Test-taking strategies of high and low mathematics achievers', The Journal of Educational Research, 99(3), pp. 144-155.

[13] Lewandowski, L. J., Berger, C., Lovett, B. J., \& Gordon, M., (2016). 'Test-taking skills of high school students with and without learning disabilities' Journal of Psychoeducational Assessment, 34(6), pp. 566-576.
[14] Bensley, D. A., Rainey, C., Murtagh, M. P., Flinn, J. A., Maschiocchi, C., Bernhardt, P. C., \& Kuehne, S., (2016). 'Closing the assessment loop on critical thinking: The challenges of multidimensional testing and low test-taking motivation'. Thinking Skills and Creativity, pp. 21, 158168.

[15] Stenlund, T., Eklöf, H., and Lyrén, P. E., (2017). 'Group differences in test-taking behaviour: An example from a high-stakes testing program'. Assessment in Education: Principles, Policy \& Practice, 24(1), pp. 4-20.

[16] Roland G. Fryer, Jr. and Steven D. Levitt, (2010). 'An empirical analysis of the gender gap in mathematics'. American Economic Journal: Applied Economics, 2, 210240.

[17] Christopher Cornwell, David B. Mustard, and Jessica Van Parys (2013). 'Noncognitive Skills and the Gender Disparities in Test Scores and Teacher Assessments': Evidence from Primary School J. Human Resources, pp 48:236-264.

[18] Georg Graetz and Arizo Karimi ‘Explaining gender gap variation across assessment forms' Available on http://hdl.handle.net/10419/2014724.

[19] Dylan, Geiger and Mark Long. "Why are men falling behind? Gender gaps in college performance and persistence. The Annals of the American Academy of Political and Social Sciences.

[20] DeKeyser, R. M. (2007). 'The future of practice (2007). In R. M. DeKeyser (Ed.), Practice in a second language: Perspectives from applied linguistics and cognitive psychology". Cambridge University, Press, pp.287-304.

[21] Rohrer, D., (2009),'The effects of spacing and mixing practice problems'. Journal for Research in Mathematics Education, pp. 4-17.

[22] Riccomini, P. J., Smith, G. W., Hughes, E. M., \& Fries, K. M., (2015).'The language of mathematics: The importance of teaching and learning mathematical vocabulary. Reading \& Writing Quarterly, 31(3), pp.235252 .

[23] Mertler, C. A., (2016).'Classroom assessment: A practical guide for educators'. Taylor \& Francis.

[24] Reddy, M. Y., (2007). 'Rubrics and the enhancement of student learning'. Educate, 7(1), pp. 3-17.

[25] Simon, M and Forgette-Giroux, R., (2001). 'A rubric for scoring academic skills'. Practical Assessment, Research and Evaluation, 7, 18 (Online, http://pareonline.net/getvn.asp).

[26] Gbafournia N., (2013).'The relationship between using multiple-choice test-taking strategies and general language proficiency levels'. Procedia - Social and Behavioral Sciences, 70 , pp. $90-94$.

[27] Samson, G. E. 1985). 'Effects of training in test-taking skills on achievement test performance: A quantitative 
International Journal for Cross-Disciplinary Subjects in Education (IJCDSE), Volume 11, Issue 2, 2020

synthesis'. Journal of Educational Research, 78 (5), pp 261266.

[28] Wiliam, D., \& Thompson, M. (2017). Integrating assessment with learning: What will it take to make it work? In The future of assessment (pp. 53-82). Routledge. 